University of Wollongong

Research Online

Faculty of Engineering - Papers (Archive)

Faculty of Engineering and Information

Sciences

$1-1-2008$

\title{
An effective permeability model to predict field-dependent modulus of magnetorheological elastomers
}

\author{
X. Z. Zhang \\ University of Wollongong, xianzhou@uow.edu.au \\ W.H. Liu \\ University of Wollongong, weihuali@uow.edu.au \\ Kosasih \\ University of Wollongong, buyung@uow.edu.au \\ X.C. Zhang \\ University of Wollongong \\ X.L Gong \\ University of Science and Technology of China
}

See next page for additional authors

Follow this and additional works at: https://ro.uow.edu.au/engpapers

Part of the Engineering Commons

https://ro.uow.edu.au/engpapers/4124

\section{Recommended Citation}

Zhang, X. Z.; Liu, W.H.; Kosasih; Zhang, X.C.; Gong, X.L; and Zhang, Q.P.: An effective permeability model to predict field-dependent modulus of magnetorheological elastomers 2008, 1910-1916.

https://ro.uow.edu.au/engpapers/4124

Research Online is the open access institutional repository for the University of Wollongong. For further information contact the UOW Library: research-pubs@uow.edu.au 


\section{Authors}

X. Z. Zhang, W.H. Liu, Kosasih, X.C. Zhang, X.L Gong, and Q.P. Zhang 


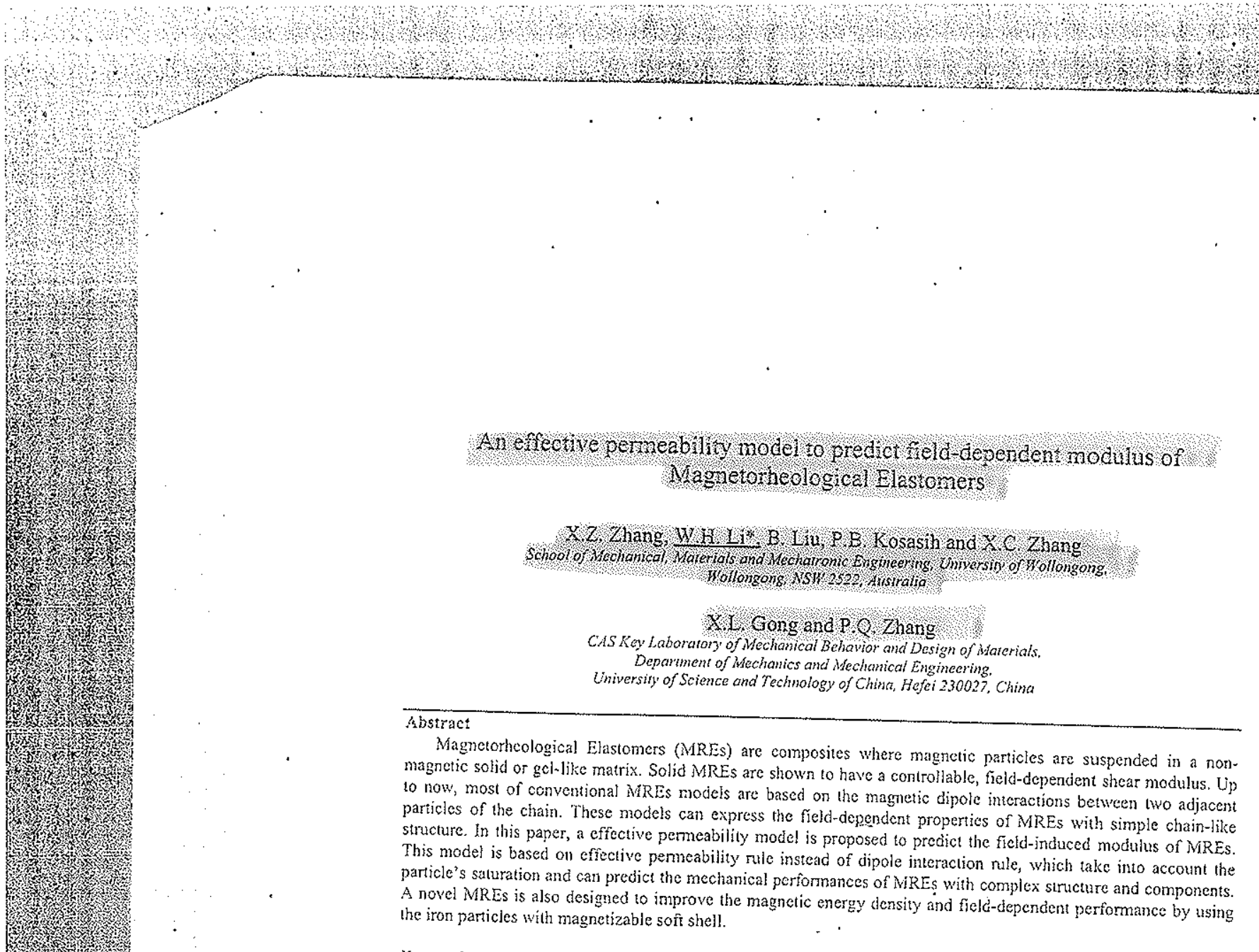

Keynords; magnetorheological elastomers, mechanical properties, magnetic field, field-dependent shear modulus

\section{Introduction:}

Magnetorheological (MR) material is a class of smart materials whose rheological properties can be controlled rapidly and reversibly by the application of an external magnetic field. Traditionally, it is materials typically consist of micron-sized while $M R$ elastomers became a new branch of them. $M R$ materials typically consist of micron-sized magnetic particles suspended in a non-magnetic matrix. The magnetic interactions between particles in these composites depend on the magnetization orientation of and giving rise to a number of interesting magnetomecoung the magnetic and strain fields in these materials and giving rise to a number of interesting magnetomechanical phenomena [1-6].

MR elastomers (MREs) are composites where magnetic particles are suspended in a non-magnetic be grouped (e. into. The particles inside the elastomer can be homogeneously distributed or they can magnetic field is applied thin like columnar stmctures). To produce an aligned particle structure, the magnetic field is applied to the polymer composite during crosslinking so that the columnar structures can properites to the viscoelastic materials properties of these elastomers been explored [7.11].

MREs have a controllable, fiedd-dependent modulus while MR fluids and MR foan have a fielddependent yield siress. This makes the two groups of materials complementary rather than competitive to

* Coresponding anthor. Phonc: $\div 61242213490 ;$ Fax: +61242213101.
E-moil address: weihuali@uow.edu.au 
each other. In other words, the stengtin of $\mathrm{M}$ fluids is characterized by their held dependent yield stess while the strengh of MREs is ypically characterized by their field dependent modulus. Oher obvious advantages of MiEs are that the particles are not able to sette with time and that there is no need for containers to keep the $M R$ materia! in place. Because the chain-like or columnar structures have been locked in the rubber-like matrix during curing, the particles need no time to arange again while hives are applied an external magnetic field, thus the response time of MREs is much less than that of MR fluids (several ins).

MiR fluids' field-dependent yield stress makes then to be widely used in various snart devices, such as danpers, clutches, and brakes. There is little doubt that there are numerous applications that can make use of controllable stiffness and others unique characteristics of MREs, such as adantive tuned vibration absorbers (TVAs), tuneable stiffiness mounts and suspensions, and variable impedance surfaces. [2, 4].

There are many models of MREs have been developed. The mechanical properties of MREs can be divided into two distinctive regimes: the composite properties without applied magnetic field and the composite properties with applied magnetic fick. Usually the host composite in MREs is a rubber-like material with a noninear stress-strain relationship. Ogden's model has been widely used to model rubberlike materials[8]. MREs modulus is also a function of filler (iron particles) volume fraction and their zerofield modulus can be given by Guth model [12]. Most models of MR material field-dependent behavior arc based on the magnetic dipole interactions berween two adjacent particles of the chain. Ginder et al. and Davis $[5,12]$ have used finite element analysis method (FEM) to determine the values of the modulus under a varied magnetic field. For elastomer composites containing magnelically sof particles dispersed in natural rubber, a $40 \%$ maximum change in modulus was observed upon the application of a saturating magnetic field. The theoretical approaches show that the maximum shear modulus increment of conventional MREs is about 50\% [12]. These dipole models can explain the simple ball-chain stucure but did not take into account the complex structure or mixed components. The intergradation between unsaturation and saturation of MREs is very hard to be expressed by these models too. In order to fabricate high quality MREs, the complex structure and components ought to be presented, and a new model of MREs must be used to explain the mecinanical properties of them.

In this paper, a new model of MREs is presented to explain field-induced modulus of MREs with complex structure and components and the particle's saturation is taken into account. A novel structure NiREs is also be introduced for example.

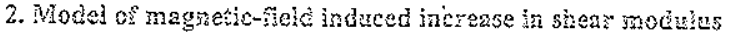

In this chapter, the conventional MRES with simple chain-like structure are presented to introduce a new effective permeability model at first. Then, the field-induced modulus of MREs with complex stiucture can be predicted by this model because the conventional magnetic dipole and correktive theory can not explain the field-induced modulus of such complex stnucture. Finally, the conparison with conventional and nove! MREs' ficld-dependent modulus is given.

For stnctural constructions as shown in Figure l (b), by using the Maxwell Gameit mixing rule [13], the effective permeability of chains can be predicted as:

$$
\mu_{c o f f}=\mu_{m}+2 \phi \mu_{n 1} \frac{\mu_{p}-\mu_{m}}{\mu_{p}+\mu_{m}-\phi\left(\mu_{p}-\mu_{m}\right)}
$$

Here, particles have permeability $\mu_{p}$ and that of matrix is $\mu_{m}$, radius of particle is $R$, distance between adjacent particles is $d$, volume fraction of particles is $\phi_{p}$, volume fraction of particles in column is $\phi=4 R / 3 d$, volume fraction of column structure in NREs is $\phi_{c}=\phi_{p} / \phi=3 \phi_{p} d / 4 R$. (The column is composed of the particles chain and the rubber between the particles.)

At the cross-section normal to the columus, the MREs are composed by columns domain and matrix domain. The effective permeability along the direction of columns is calculated by parallel-comection rnte:

$$
\mu_{c f f}=\sum_{i=1}^{n} \phi_{i} \mu_{i} \quad \text { and } \quad \sum_{i=1}^{n} \phi_{i}=1
$$

where the $\phi_{i}$ and $\mu_{i}$ are the volume fraction and relative permeability of component $i$

So the effective relative permeability of conventional MiREs is:

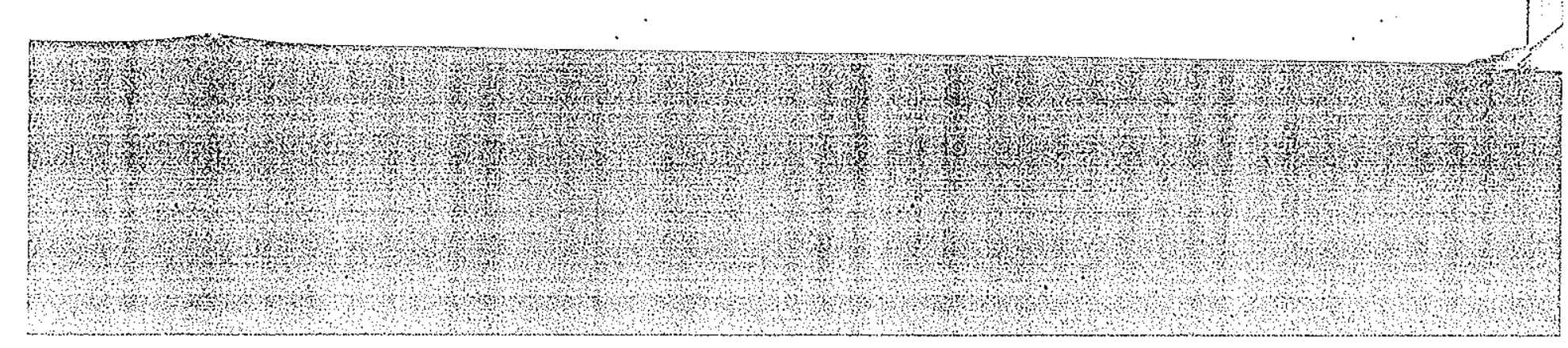




$$
\mu_{c t j}=\mu_{c i f f} \phi_{c}+\mu_{m}\left(1-\phi_{c}\right)=\mu_{m}+2 \phi_{p}, \mu_{m i} \frac{\mu_{p}-\mu_{m}}{\mu_{p}+\mu_{m}-\frac{4 R}{3 d}\left(\mu_{p}-\mu_{m}\right)}
$$

According to the equation: $\tau=-\frac{1}{2} \mu_{0} H_{0}^{2} \partial \mu_{\text {orr }}(\varepsilon) / \hat{\partial} \varepsilon$ [14] and $\varepsilon=\% / d$ for shear mode (As show in Fig. 2), the shear stress of MREs can be expressed as:

And shear modulus is:

$$
\tau=12 \phi_{p} \mu_{0} \mu_{m}\left(\frac{R}{d}\right) H_{0}^{2} \frac{\left(\mu_{p}-\mu_{m}\right)^{2} \varepsilon}{\sqrt{1+\varepsilon^{2}}\left[3 \sqrt{1+\varepsilon^{2}}\left(\mu_{p}+\mu_{m}\right)-4\left(\frac{R}{d}\right)\left(\mu_{p}-\mu_{m}\right)\right]^{2}}
$$

$$
G=12 \phi_{p} \mu_{0} \mu_{m}\left(\frac{R}{d}\right) H_{0}^{2} \frac{\left(\mu_{p}-\mu_{m}\right)^{2}}{\sqrt{1+\varepsilon^{2}}\left[3 \sqrt{1+\varepsilon^{2}}\left(\mu_{p}+\mu_{m}\right)-4\left(\frac{R}{d}\right)\left(\mu_{p}-\mu_{m}\right)\right]^{2}}
$$

Because $\varepsilon \ll 1, \mu_{p} \gg \mu_{m}$, and $R / d \approx 1 / 2$, the equation can be simplified as:

$$
G \approx 6 \phi_{p} \mu_{0} \mu_{m} H_{0}^{2}
$$

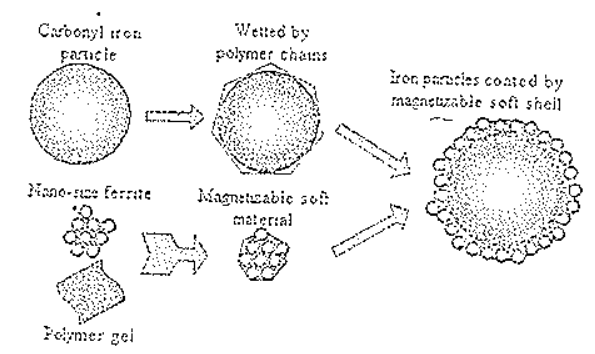

(a) Fabricate process

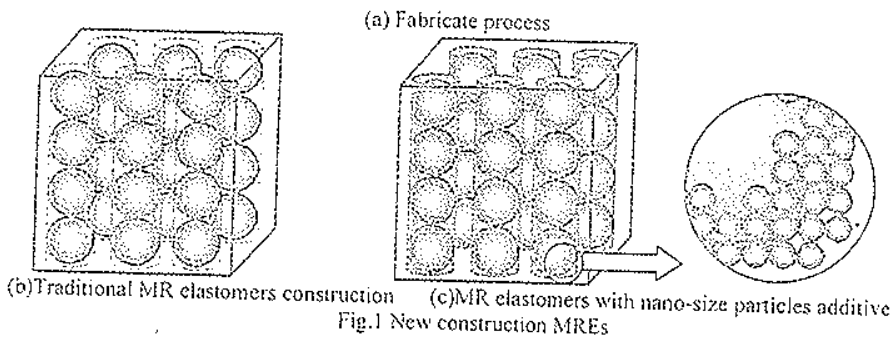

Fig.l New construction MRES

Conventional MREs is general composed of magnetizable particles with average diameter about several microns and polymer matrix such as nubber [2]. In this paper, a new material design is used to with magnetizable soft shell MREs. Different from conventional methods, the iron particles are coated in order to fabricate this kind of mased of nano-size ferrile powder and polymer gel. As shown in Fig. l (a), Firstly, it is needed for forming a continule soft shell, nano-size ferrite and polymer gel are pre-requisite. Then mix the nano-size particles with polynor composite structure to wet the particles by polyner chains. micro-size paricles with the soft molymer to produce the sof magnetism material. After that, coat the rubber matrix to fabricate rubber matrix to fabricate MREs. At last, the mixture is poured into a mould and a strong external With this particles chains. Thus, this method shell will deform and fill in the void space exising in micro-size Marticles chains. Thus, this method will increase the pack/energy density the effective permeability of shear modulus depends on the energy, and consequently will improve the MRE performances because the 


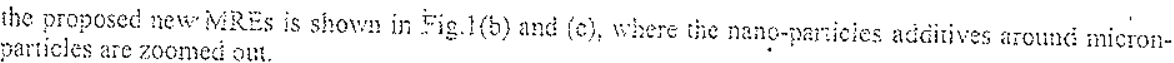

(3)

shown

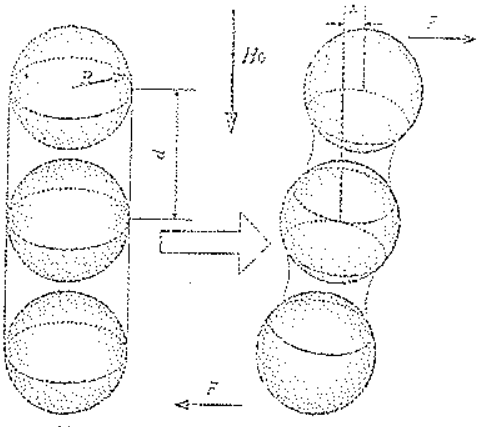

Fig.2 The shear model of particles chain

For novel MREs, the column structure without deformation is composed of micro-particles and soft shell. When MREs are deformed by force, the distance between particles is increased, some matrix around the column intrudes the column to refill the gap and the effective permeability is changed too. The changes result in the increase of magnetic energy and the fjeld-dependent modulus of MiREs (Fig.2).

The magnetizable soft shell is composed of nano-particles and rubber and the volume fraction of nano-particles in soft shell is $\phi_{n}$. At the shear mode, when the shear strain is $\varepsilon=x / d$, the volume fraction of particles (including nano-size and micro-size particles) in the colunim can be expressed as:

$$
\phi_{p z}=\frac{4 R+\phi_{n}(3 d-4 K)}{3 d \sqrt{1+\varepsilon^{2}}}
$$

By using the same deduction as above-mentioned, the shear modulus of nano-additive MiREs is:

$$
G_{n}=\frac{3}{4} \phi_{p} \mu_{0} \mu_{m}\left(\frac{d}{R}\right) H_{0}^{2} \frac{\left(\mu_{p}-\mu_{m}\right)^{2}\left[\frac{4 R}{d}\left(\phi_{n}-1\right)-3 \phi_{n}\right]^{2}}{\sqrt{1+\varepsilon^{2}}\left\{3 \sqrt{1+\varepsilon^{2}}\left(\mu_{p} \div \mu_{m}\right)+\left[\frac{4 R}{d}\left(\phi_{n}-1\right)-3 \phi_{n}\right]\left(\mu_{n}-\mu_{m}\right)\right\}^{2}}
$$

Because $\varepsilon<<1, \mu_{p}>>\mu_{m}$, and $R / d \approx 1 / 2$, the equation can be simplified as:

$$
G_{n} \approx \frac{3}{2} \phi_{p} \mu_{0} \mu_{m} H_{0}^{2}\left(\frac{2+\phi_{n}}{1-\phi_{n}}\right)^{2}
$$

When $\phi_{n}=0$, equation 9 has the same form as equation 6

Actually, the relative permeability of particles is the function of magnetic field intensity and if the saturation ought to be taken into account, it is just need replace $\mu_{p}$ by $\mu_{p}(H)$ in equation 9 , where $\mu_{p}(H)$ can be obtained by experiment

Here an empirical equation about $\mu_{p}(H)$ is given as $[15]$ :

$$
\mu_{p}(H)=\frac{H\left(\mu_{p}-1\right)+\mu_{p} M_{s}}{H\left(\mu_{p}-1\right)+M_{s}}
$$

where $\mu_{p}$ is the largest relative permeability of particles, and $M_{s}$ is the saturation magnetization and $\mu_{0} M_{s}=2.1 \mathrm{~T}$ for Fe.

Assuming the relative permeability of particles is 1000 original and that of matrix is 1 , the volume fraction of micro-paritcles in MREs is $27 \%$ and the volume fraction of nano-particles in magnetizable soft shell is $27 \%$ too, the field-dependent shear modulus of conventional MREs and that of the novel MREs are calculated and shown in Fig.3. Obviously, if the iron particles arc covered by magnetizable soft sirell, the shear moduhus is increased significantly.

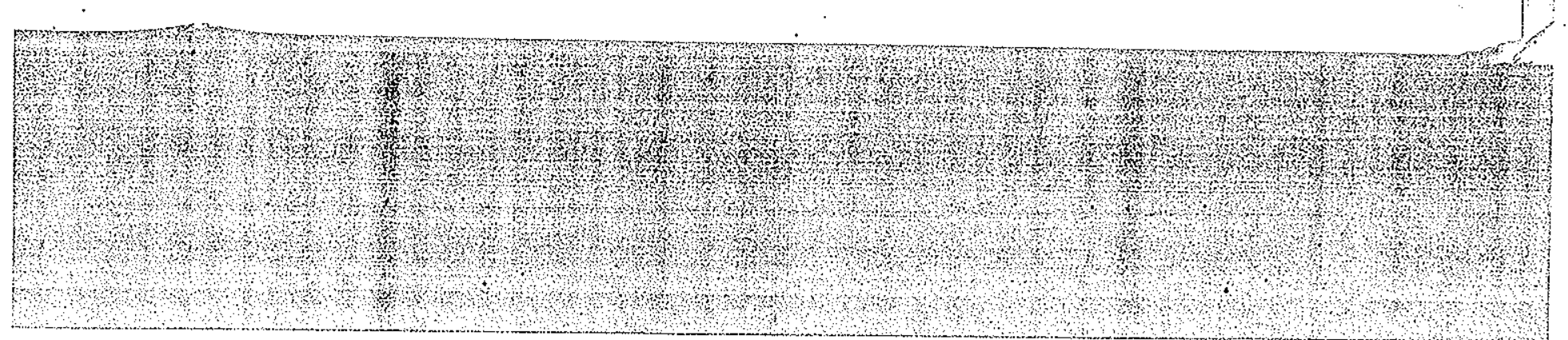




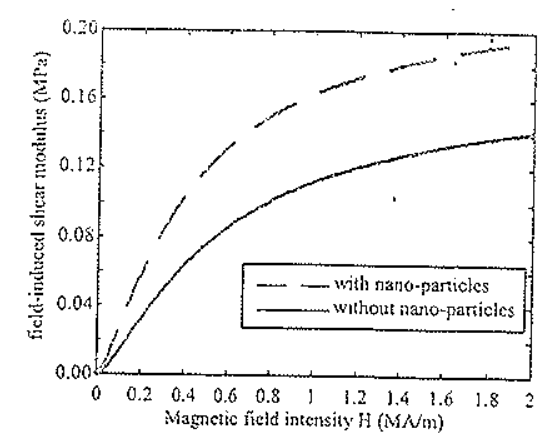

Fig. 3 The predicted field dependent shear modulus

\section{Zaro-field sinear modulus}

The mechanical properties of MREs without applied magnetic field can use the conventional model to predict. The material can be seen as the composite properties with different filler. The approximated shear modulus $G_{\text {ran }}$ of elastomer filled with randomly distributed, spinerical rigid particles is simply given by the equation [12]:

$$
G_{r a n}=G_{0}\left(1+2.5 \phi_{i}+14.1 \phi_{1}^{2}\right)
$$

where $G_{0}$ is the shear modulus of the unillled elastomer and $\phi_{t}$ is the volume fraction of filler. The modulus calculated by this equation is similar to the value of anisorropic MREs [12].

According to the Chapter 3 , the volume fraction of filler in novel MiREs is $\phi_{t}=\phi_{p}\left[4 R+\phi_{n}(3 d-4 R)\right] / 4 R$. Fixing the volume fraction of nano-size particles in film is $27 \%$ and $R / d=1 / 2$, the zero-field shear modulus can be calculated and shown in Fig.4.

According to the Fig.4, the added nano size magnetism film can hardly improve the zero-field shear
odulus of MREs. modulus of $\mathrm{MRES}$.

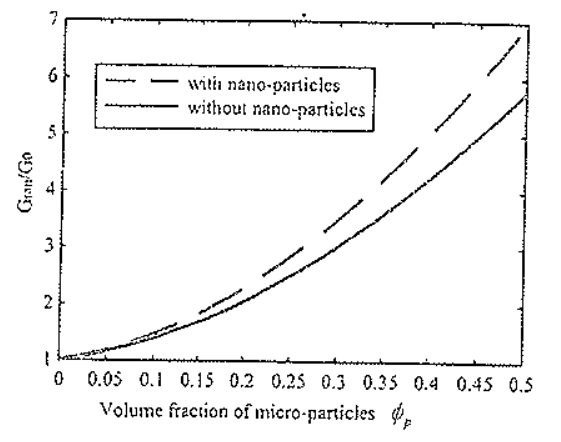

Fig. 4 the predicted zero-ficld shear modulus

\section{Conciusion}

In this paper, a new equivalent permeability model is presented to explain field-induced modulus of MREs with complex structure and components. This model is based on efficiency permeability rule and
takes into account the particle's sanuation.

A novel stncture MREs is also be introduced as an example. It is designed to improve the magnetic energy density and field-dependent performance. The new method will use the iron particles which are coated with magnetizable soft shell composed of nano-size ferrite powder and polymer gel. Mechanical performances of the newly proposed MREs are expected to be improved. 
According to the simulated results, the novel MREs have the much larger field-dependent modult: than that of conventional ones. At the same time, the zerofield shear nodilus of the ans is not improved obviously by tsing the magnetizable soft silit.

\section{geVerencer} 11) Shiga T, Okada A, Kurauchi T. Wagnectroviscoelastic behavior of composite gels, J. Applied Polymer Science 58 (1995)
$787 \ldots 792$.

(2) Ginder MM, Nichols ME, Elic LD, Tardiff JL. Wagnetorheological elastomers: propertics and applications, SPIE - The Intemational Socicty for Optical Enginecring. Proceedings of the 1999 Smart Structures and Matcrials on Sman Materials

[3] Carlson DD, Jolly MR. MR fluid, foam and elastomer devices, Nechatronics 10 (2000):555-569. 4) Li WH, Yao GZ, Chen G, Yco Sli, Yap FF, Testing and Steady State Wodeling of a Lincar MR Damper under Sinusoida:
Loading, Smart Mater. Struct., 9(2000): 95-102. [5] Zhang $X Z$, Zhang $\mathrm{PQ}$, Gong $X \mathrm{X}$., Wang QM Study on the mechanism of the squecze-strengthen cffect in magnetorhcological
fhids, J. Appl. Phys, $96(2004): 2359-2364$.

I mode

imated

cles is

(11)

ion of

Es is

$\%$ and

Isluear [6] Demchuk $S A$, Kuzmin VA. Viscowastic propertics of magnetorheological elasiomers in the regime of dynamic deformation,
J. Engineering Physics and Thermophysics $75(2002): 396-400$.

(7) Lokander $\mathrm{W}$, Sienberg B. Improving the magnetorhcological effect in isotropic magnetorheological nubber materials, (2003): 677-680 Materiat Systems and Structures 15 (2004): 27-35.

9] Yalcintas $M$, Dai $H$. Vibration suppression capabilities of magnetorheological materials based adaptive structures, Smar:

[10] Dorfman A, Ogden RW. Magnetoelastic modeling of elastomers, European J. Mechanics A/ Solids 22 (2003);497,-507.

[11] Farshad $\mathrm{M}$, Benine A. Magnetoactive elastomer composites, Polymer Testing 23 (2004):347-353.

[12] Davis LC. Model of magnetorheological elastomers, J. Applied Phys, S5(1999):3348-3351.

feee Transactions on Geosien Aikoskinen KL. Effective Permintivity of Mixtores: Numerical Validation by the FDTD Wethod, lece Transactions on Geoscience And Remote Sensing, 38(2000):1303-1308.

[14] Davis LC. Polarization Forces and Conductivi-ty Effects in Electrorheological Fluids, J.Appl.Phys, 72 (1993):1334-1340.

3410.3412 . 